\title{
Anti-Oxidative Biomarkers in Newborn Kids of Aardi Goats
}

\author{
M. J. Al-Hassan1, H. E. Mohamed2², K. A. Al-Samawi' ${ }^{3}$, M. A. Al-Badwi ${ }^{1}$ \\ ${ }^{1}$ Department of Animal Production, Faculty of Food and Agricultural Sciences, King Saud University, Riyadh, Saudi Arabia \\ ${ }^{2}$ Department of Basic Medical Science, Faculty of Applied Medical Sciences, Al Baha University, Al Baha, Saudi Arabia \\ ${ }^{3}$ Department of Animal Production, Faculty of Agricultural Sciences and Veterinary Medicine, Thamar University, Dhamar, \\ Yemen \\ Email: *mjalhassan@gmail.com
}

How to cite this paper: Al-Hassan, M.J., Mohamed, H.E., Al-Samawi, K.A. and AlBadwi, M.A. (2017) Anti-Oxidative Biomarkers in Newborn Kids of Aardi Goats. Agricultural Sciences, 8, 1168-1172. https://doi.org/10.4236/as.2017.810085

Received: December 29, 2016

Accepted: October 27, 2017

Published: October 30, 2017

Copyright (c) 2017 by authors and Scientific Research Publishing Inc. This work is licensed under the Creative Commons Attribution International License (CC BY 4.0).

http://creativecommons.org/licenses/by/4.0/

(c) (i) Open Access

\begin{abstract}
The provision of basic data about oxidative stresses on Aardi goats will be beneficial for understanding the basic physiological indices of a valuable local breed of goats under harsh desert condition. The primary aim of this study is to assess the antioxidant status of newly born Aardi kids. Eighteen newly born Aardi kids were used in this study; sampled weekly as from week 1 to 4 for the assay of the plasma Total Antioxidant Capacity (TAC), ThioBarbituric Reactive Substances (TBARS), and Superoxide Dismutase (SOD) activities. For new-born, total blood antioxidants concentrations did not change during the four weeks of life. However, TBARS increased during the $2^{\text {nd }}$ and $3^{\text {rd }}$ week of age $(\mathrm{p}<0.05)$. The results indicated that TAC in kids from birth to 4 weeks of age tended to increase, but not significantly. Serum TBARS concentrations increased on the $2^{\text {nd }}$ week and decreased significantly on the $4^{\text {th }}$ week of age. Serum SOD levels did not change significantly, even though, the trend showed a decline during $1^{\text {st }}$ to $3^{\text {rd }}$ week of age. The small decrease in serum TBARS in the serum of kids can be considered as an indication of decreased oxidants, which in turn, resulted in a reduction in serum SOD concentration. In conclusion, this basic data could help in understanding the adaptational physiology of young local Saudi goats.
\end{abstract}

\section{Keywords}

Aardi Kids, Antioxidant, Serum

\section{Introduction}

Antioxidants are chemicals that inhibit the oxidations of other chemicals. They are involved in preventing damages to cells in the body. It is well-documented 
that the balance between oxidants and antioxidants may be impaired in neonatal animals. Aardi is an important local Saudi goats, with proven adaptation to arid environment [1]. Publications concerning the normal and abnormal levels of total as well as individual antioxidant profiles in Saudi breeds of ruminants are lacking. However, limited information is available on physiological changes in oxidative biomarkers in newborn and young Local breeds of goats in Saudi Arabia. Therefore, this study aims at assessing the antioxidant status at different intervals in local Saudi goat kids during the first month of life.

\section{Materials and Methods}

Eighteen newly born Aardi kids (12 female and 6 male) were used in this study, and they were sampled weekly as from week 1 to $4^{\text {th }}$ week of life for a period of 2 months (during February and March). Those newly born kids are from goats that were bred in our department experimental station. Blood samples were collected for the assay of Total Antioxidant Capacity (TAC), ThioBarbituric Reactive Substances (TBARS), and Superoxide Dismutase (SOD) activities (Cayman kits, USA). The changes in theses biomarkers were analyzed by means of ANOVA repeated measures. Data were expressed as the mean \pm SE for all parameters. Fisher's least significant difference (LSD) was used at a level of $\mathrm{p}<0.05$. All data were analyzed using SAS program (SAS Inst. Inc., Cary, NC).

\section{Results and Discussion}

The primary aim of this study was to assess the antioxidative profile of newly born Aardi kids. Oxidative stress biomarkers can provide highly relevant insights into the physiological state of an organism [2]. The antioxidative defense is related to time and the oxidation process of protein [3], and transportation as seen in buffalo calves [4], and the feeding on artificial milk replacer [5].

Measuring each antioxidant separately is difficult; though, several methods have been devised to measure TAC [6]. The current results indicated that TAC in kids from birth to 4 weeks of age tended to increase, but not significantly (Figure 1). It is postulated that TAC serum concentration in kids is associated with the maternal health and nutrition [7]. Serum TBARS concentrations increased on the $2^{\text {nd }}$ week and decreased significantly on the $4^{\text {th }}$ week of age (Figure 2). These insignificant changes might reflect that kids' ROS are not high enough to be recognized, and Malondialdehye (MDA) levels $3.060 .69 \mathrm{mmol} / \mathrm{L}$ ), and TAS $829.2623 .16 \mathrm{mmol} / \mathrm{L}$ in neonates [8].

As stated earlier, SOD converts SOD converts oxygen free radicals $\left(\mathrm{O}_{2}^{-}\right)$into $\mathrm{H}_{2} \mathrm{O}_{2}$ and Oxygen, and its activity is related to the presence of reactive oxygen metabolites. Serum SOD concentrations did not change significantly, even though, the trend showed a decrease during $1^{\text {st }}$ to $3^{\text {rd }}$ week of age (Figure 3 ). The small decrease of the serum TBARS in serum of kids can be considered as an indication of decreased oxidant, which in turn, resulted in a decrease in serum SOD concentration. 
Our data are in line to previous studies performed in women and cattle [9]. Parallel trends for SOD and TAC found in this study indicate a fully functioning antioxidant defense system in the calf, which is well adjusted to and able to compensate the inevitable oxidative stress of birth [10]. Values of oxidative stress markers in newborns immediately after birth were elevated and increased further during the first few days of neonatal life [11].

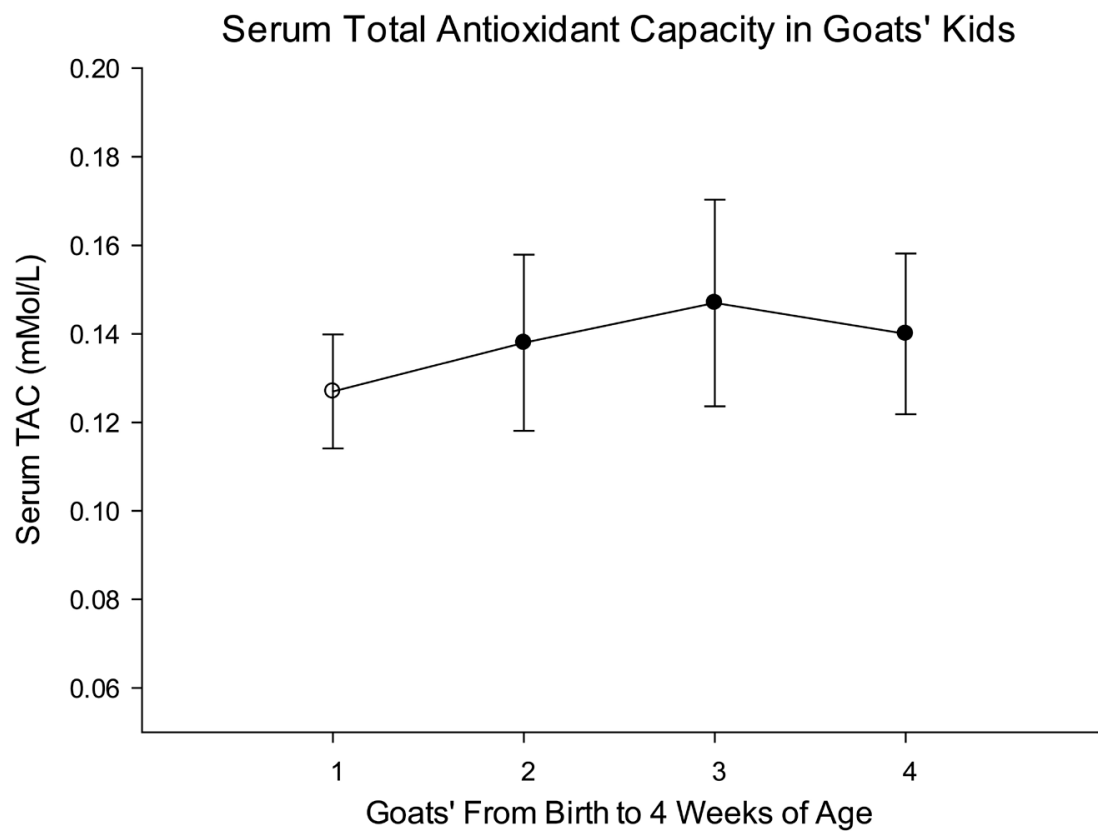

Figure 1. Serum Total Antioxidant Capacity in goats' kids at 1 to 4 weeks of age. Values are expressed as means \pm SE.

\section{Serum TBARS in Goats' Kids}

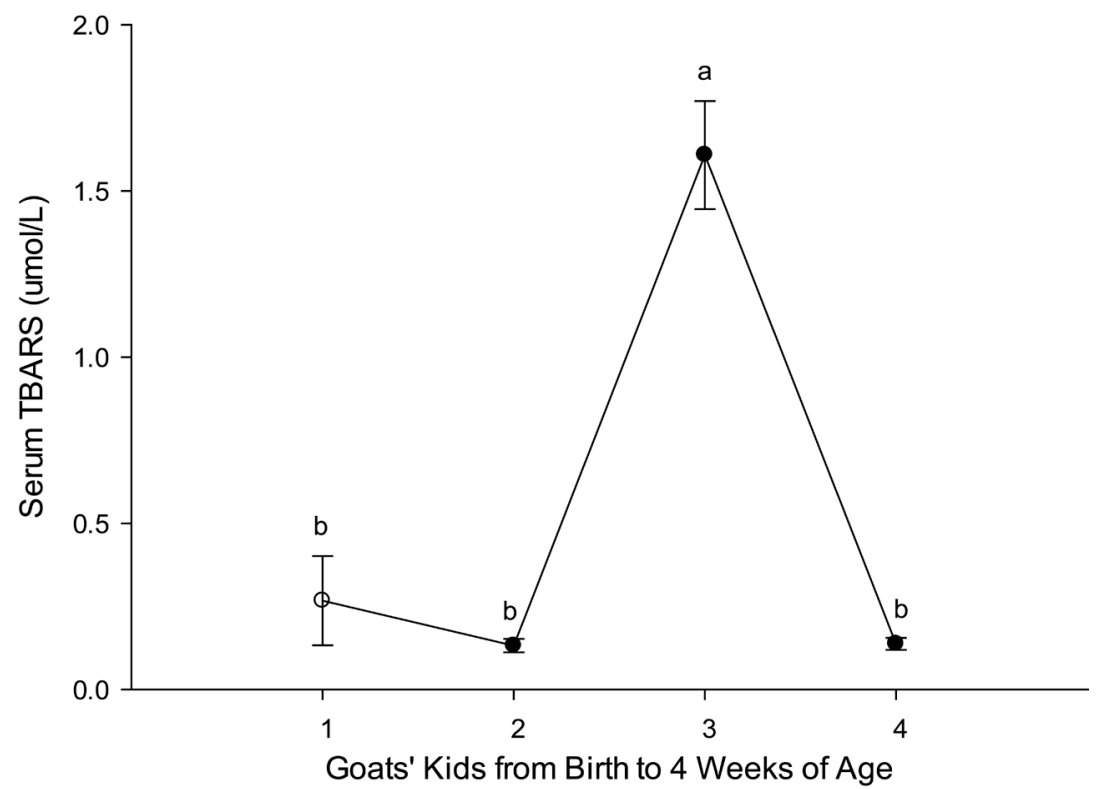

Figure 2. Serum TBARS in goats' kids at 1 to 4 weeks of age. Values are expressed as means \pm SE. Values with different scripts are statistically $(\mathrm{p}<0.05)$ different. 


\section{Serum SOD Activity in Goats' Kids}

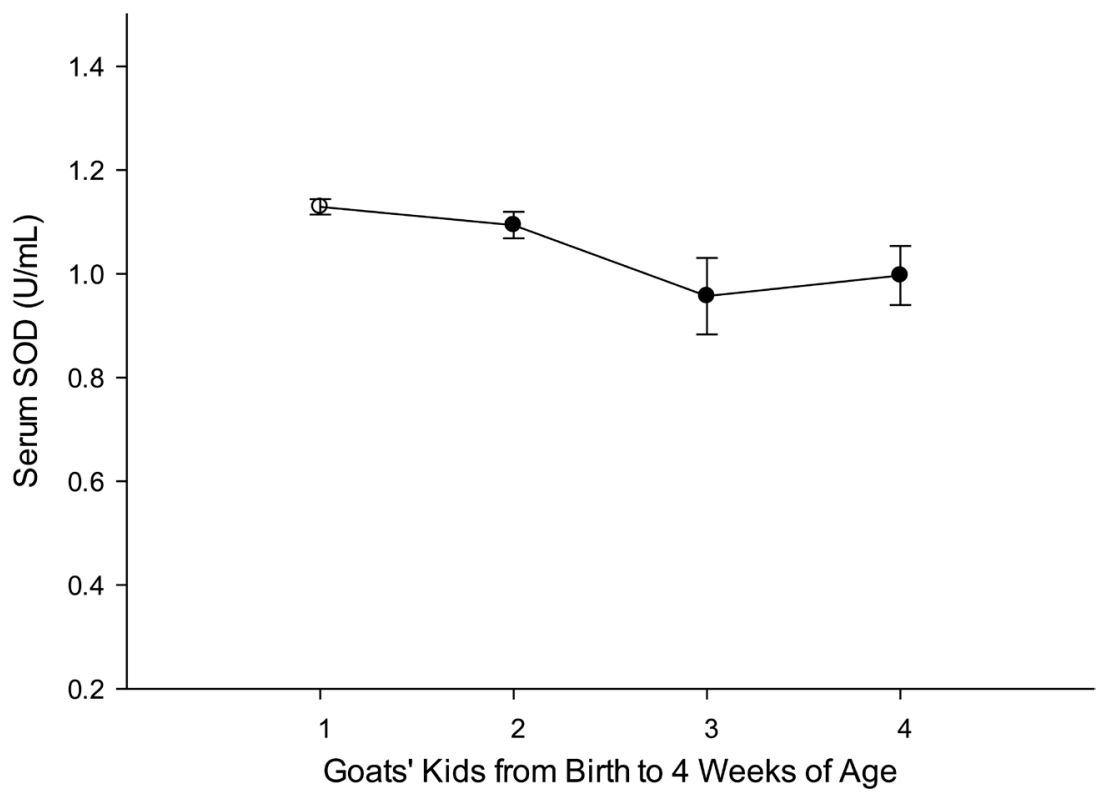

Figure 3. Serum SOD in goats' kids at 1 to 4 weeks of age. Values are expressed as means \pm SE.

To the best of our knowledge, this study provides, for the first time, basic data about oxidative stresses on Aardi goats kids. Our results gave us very close details on the animals during such important period, where we can go further to reduce such stresses to improve Aardi goats' productivity. While this study shed the light on the basic oxidative stresses on Aardi goats' kids, the small number of animals used limited it. For that reason, we could not include the effect of gender on the parameters studied.

\section{References}

[1] Al-Atiyat, R.M. and Aljumaah, R.S. (2014) Genetic Relatedness between Ardi, Black Bedouin and Damascus Goat Breeds. Genetics and Molecular Research, 13, 46544665. https://doi.org/10.4238/2014.June.18.8

[2] Rodriguez-Estival, J., Garcia-de Blas, E. and Smits, J.E.G. (2016) Oxidative Stress Biomarkers Indicate Sublethal Health Effects in a Sentinel Small Mammal Species, the Deer Mouse (Peromyscus maniculatus), on Reclaimed Oil Sands Areas. Ecological Indicators, 62, 66-75. https://doi.org/10.1016/j.ecolind.2015.11.019

[3] Ranade, R., Talukder, S., Muscatello, G. and Celi, P. (2014) Assessment of Oxidative Stress Biomarkers in Exhaled Breath Condensate and Blood of Dairy Heifer Calves from Birth to Weaning. The Veterinary Journal, 202, 583-587. https://doi.org/10.1016/j.tvjl.2014.10.025

[4] El-Deeb, W.M. and El-Bahr, S.M. (2014) Acute-Phase Proteins and Oxidative Stress Biomarkers in Water Buffalo Calves Subjected to Transportation Stress. Comparative Clinical Pathology, 23, 577-582. https://doi.org/10.1007/s00580-012-1654-8

[5] Abuelo, A., Perez-Santos, M., Hernendez, J. and Castillo, C. (2014) Effect of Colostrum Redox Balance on the Oxidative Status of Calves during the First 3 Months of Life and the Relationship with Passive Immune Acquisition. The Veterinary Journal, 199, 295-299. https://doi.org/10.1016/j.tvjl.2013.10.032 
[6] Ghiselli, A., Serafini, M. and Matella, F. (2000) Total Antioxidant Capacity as a Tool to Assess Redox Status: Critical View and Experimental Data. Free Radical Biology and Medicine, 29, 1106-1114. https://doi.org/10.1016/S0891-5849(00)00394-4

[7] Sheikhi, M., Elham, S. and Paknahad, Z. (2017) Dietary Antioxidant Capacity and Its Association with Preeclampsia. Clinical Nutrition Research, 6, 145-146. https://doi.org/10.7762/cnr.2017.6.2.145

[8] Namdey, S., Bhat, V., Adhisivam, B. and Zachariah, B. (2014) Oxidative Stress and Antioxidant Status among Neonates Born to Mothers with Pre-Eclampsia and Their Early Outcome. The Journal of Maternal-Fetal \& Neonatal Medicine, 27, 1481-1484. https://doi.org/10.3109/14767058.2013.860521

[9] Sgorbini, M., Bonelli, F., Marmorini, P., Biagi, G., Corazza, M. and Pasquini, A. (2015) Maternal and Neonatal Evaluation of Derivated Reactive Oxygen Metabolites (d-ROMS) and Biological Antioxidant Potential in the Horse. Theriogenology, 83, 48-51. https://doi.org/10.1016/j.theriogenology.2014.07.041

[10] Haser, D. and Fürll M. (2015) Age-Related Changes in Antioxidant Parameters in Healthy Calves between the First Day of Life and the 18th Month Taking into Consideration Selected Metabolic Parameters. Tierärztliche Praxis Großtiere, 43, 5-13. (In German) https://doi.org/10.15653/TPG-140481

[11] Wilinska, M., Borszewska-Kornacka, M.K., Niemiec, T. and Jakie, G. (2015) Oxidative Stress and Total Antioxidant Status in Term Newborns and Their Mothers. Annals of Agricultural and Environmental Medicine, 22, 736-740. https://doi.org/10.5604/12321966.1185786 